\title{
Efficacy of nutrition counselling on energy and micronutrient intake of pregnant women in Migori County, Kenya
}

\author{
Florence. O. Odiwuor ${ }^{1 *}$, Judith Kimiywe ${ }^{2}$ and Judith Waudo ${ }^{2}$ \\ 1Department of Agribusiness, School of Agriculture, Natural Resources and Environmental Studies, Rongo University, \\ P.O. Box103, Rongo, Kenya. \\ 2Department of Foods, Nutrition and Dietetics, School of Applied Human Sciences, Kenyatta, University, P.O. Box \\ 43844, Nairobi, Kenya. \\ ${ }^{*}$ Corresponding author. Email: florenceoddy@gmail.com
}

Copyright (C) 2017 Odiwuor et al. This article remains permanently open access under the terms of the Creative Commons Attribution License 4.0, which permits unrestricted use, distribution, and reproduction in any medium, provided the original work is properly cited.

Received 14th October, 2017; Accepted 6th November, 2017

\begin{abstract}
A large number of pregnant women in many parts of the world enter pregnancy at sub-optimal weight. More than $60 \%$ of Kenyan population suffers from food insecurity. The result is malnutrition which primarily affects pregnant women and children and significantly contributes to their morbidity and mortality. Maternal nutrition is critical for both mother and child as it lays fundamental foundation for the successful outcome of pregnancy. This study sought to assess changes in energy and selected micronutrient intakes after nutrition counselling among pregnant women in Migori County. A Prospective Cohort study design was used and simple random sampling was used to recruit a sample of 150 pregnant women who were enrolled into a nutrition counselling programme. Data was collected by 24 hour recall and food frequency and analyzed by Nutri-Survey computer package and SPSS Analysis Software. Relationships between variables were tested by t-tests. Generally, there was improved dietary intake of all nutrients after counselling although some did not meet the RDA even after counselling. $4.4 \%$ and $20.9 \%$ of the women had intakes above RDA for energy, at baseline and after counselling respectively, $62.5 \%$ and $84.3 \%$ had intakes above RDA for protein at baseline and after counselling respectively. Carbohydrate intake had $93.9 \%$ within or above RDA at baseline while all met the RDA after counselling. $61.2 \%$ and $77.4 \%$ were able to meet the RDA for vitamin A at baseline and after counselling respectively. Only $13.5 \%$ met the RDA for folic acid and iron each at baseline but after counselling all had intakes below RDA. The finding is important to central and local governments, civil society, intergovernmental agencies, research groups, business enterprises and community under study. The study fills the knowledge gap and therefore contributes to the advancement of knowledge.
\end{abstract}

Key words: Nutrient intake, pregnant women, Recommended Dietary Allowances (RDA).

\section{INTRODUCTION}

Seven hundred and ninety three million people in the world suffer from chronic hunger. Most hungry people (98\%) live in developing countries, where almost $15 \%$ of the population is undernourished. Malnutrition is the leading cause of disease in the world (FAO, 2014). Women make up a little over half of the world's population but they account for over $60 \%$ of the world's hungry (ECOSOC, 2007, Merkel, 2016). In many parts of developing countries women are responsible for performing a large portion of unpaid domestic work much of which is difficult physical labour. In sub-Saharan Africa women contribute $60-80 \%$ of agricultural labour to produce food for sale and household consumption (Ransom and Elder, 2013). This makes them engage in 
high levels of activity throughout pregnancy. This energy expenditure further increases the amount of energy needed from their diet.

Maternal nutrition is critical for both mother and child as it lays fundamental foundation for the successful outcome of pregnancy (FAO, 2014). Several factors determine the choices that low income groups have regarding their food consumption and diets. Most vulnerable of all include pregnant women. Malnutrition in women including pregnant women is not conspicuous and remains to a large extent unaccounted for and unreported, thus insufficient attention has been given to its extent, causes and consequences (Black and Victoria, 2013).

Approximately 200 million women become pregnant each year in developing countries and many of these women suffer from on-going nutritional deficiencies (Leslie, 2000; Ruel, 2013, Merkel, 2016). According to FAO (2012) and Merkel (2016) a large of number of women in many parts of the world enters pregnancy at sub-optimal weight and/or height. Many others suffer micronutrient deficiencies. The most (48\%) affected groups on anaemia prevalence worldwide are pregnant women, $56 \%$ in developing countries. In Kenya, just over half $(55 \%)$ of pregnant women experience iron deficiency anaemia, about $52 \%$ experience zinc deficiency and about $40 \%$ experience vitamin A deficiency ranging from severe $(10 \%)$ to marginal (51\%) (Republic of Kenya, 2011; MoPHS and SCUK, 2011). Increased maternal requirements for physical activity combined with low micronutrient and energy intake may also reduce the supply of nutrients to the foetus. Kenya's high rates of under nutrition among women of reproductive age (WRA) are particularly due to sub-optimal feeding practices, heavy physical work and low energy and micronutrient intake (Shrimpton and Sadahha, 2011, Division of Nutrition (GOK), 2012) coupled with insufficient awareness and knowledge on nutritionally adequate diets (Republic of Kenya, Food Security and Nutrition Strategy, 2008). Improving the micronutrient and energy status of mothers can improve pregnancy outcomes.

An investment in preventing foetal under nutrition is a highly effective investment because it not only improves maternal and infant nutritional status but may also slow down or prevent the onset of chronic disease in later life. According to Black and Victoria, (2013) malnutrition is one of the most persistent barriers to growth and human development. To be able to achieve all the Sustainable Development Goals, nutrition must be up scaled because it is the driver for a healthy and active life (FAO, 2017) that can propel communities to work towards attaining these goals.

Communication for behaviour and social change based on formative research on the barriers to the facilitators of good nutrition can promote behaviour change in communities, raise awareness about nutrition services and stimulate shifts in social norms in order to improve the enabling environment for good nutrition in communities (Schultink, 2013). The Nutrition Communication Project has addressed maternal nutrition in several countries programmes. A programme among women in Thailand found that a message to measure weight gain in pregnancy was useful in encouraging women to eat more (Roesel et al, 1990). In Burkina Faso women who reported exposure counselling showed higher levels of knowledge on the dietary needs of pregnant women (NCP, 1995). The Bangladesh integrated nutrition project included a community based nutrition counselling component to bring about sustainable changes in feeding and eating behaviours of pregnant and lactating women (Quote reference). Intervention programmes for pregnant women have had little success in decreasing the high rates nutrient deficiency. A review of several of these programmes revealed that the causes of poor programme performance were, insufficient and inappropriate counselling of mothers. The study sought to assess changes in energy, vitamin A, C, calcium, iron, folic acid and zinc intakes, before and after sufficient and appropriate counselling among pregnant women in Migori County.

\section{METHODOLOGY}

The study adopted a prospective cohort study design and the pregnant women were followed up from four to seven months based on their gestation age at recruitment. The study area was Migori County. The County is located in Western Kenya bordering Homabay County on the North, Kisii County on the North East, Narok County on the East and South East, Tanzania on the South and South West and Lake Victoria to the West.

The study population were pregnant women who visited selected health care facilities to receive antenatal care. The study included all pregnant women of reproductive age (15 to 49 years) up to 26 weeks gestation, women with a documented medical history or who reported a history of disordered eating, those who resided in the county for more than 6 months and those who gave consent to participate in the study. But excluded women pregnant with multiples, and women with diabetes or hypertension prior to pregnancy, women who were bedridden, women who had resided in the county for less than 6 months and those who did not give consent to participate in the study.

Purposive sampling was used to select sub-County hospitals in Migori County for study. One quarter of the year's population projection rounded to the nearest ten thousand was used as the study population because sample selection took about three to four months. Each health facility was to provide an equivalent proportion of the sample of pregnant women. Simple random sampling 
was used to obtain the required sample size (50) of pregnant women in each of the selected health facilities. Women were sampled daily at the health facilities by the assistance of health care providers for three to four months until the required sample size was obtained. Upon recruitment into the study, baseline data was collected from each subject who was then enrolled into the counselling initiative and followed up until delivery.

The sample size was determined by use of Fisher's formula (1991) for original sample and Yamane's (1967) Formula for final sample size $n_{0}=Z^{2} p q / e^{2}$.

\section{Data collection instruments and procedures}

Twenty-four (24) hour dietary recall and food frequency was used to obtain dietary intake information. Research Assistants who also included trained registered nurses in the hospitals were trained on data collection techniques. The Health workers underwent a second training session on the nutrition flip chart on the content and on how to deliver the content to the pregnant women during antenatal care visits. The objectives of the training was to harmonize questionnaire content, to review effective adult teaching techniques, how to carry out the 24 hour recall interview, and to familiarize researchers with training materials and equipment. After the training, Researcher and Assistants preceded to the various health facilities for sample selection and recruitment. The pregnant women were selected by simple random sampling as they received antenatal care services.

The study was verbally explained to each woman and then informed consent form was issued to each woman who was also requested to read the same information, for those who could not read, the content of the form was read to them after which upon consent to participate in the study each woman had to sign the consent form before recruitment into the study. Upon recruitment, baseline data were collected after which the counseling resources were issued to each subject with instructions on how to undertake the process. Data collection was hospital based. Each participant was given a code and their names recorded against the codes to ease follow up. After the study the names were discarded and only the codes were used for data entry and analysis. From the initial total sample of 150 pregnant women, data for 136 pregnant women qualified for analysis at baseline level and data for 115 women was available for analysis after the intervention. Other pregnant women dropped out due to various factors. Only data for those who attained the four antenatal care WHO's recommended visits qualified for analysis after intervention.

The 24 hour dietary recall was administered through a face to face interview schedule. On the first day of recruitment and on the ANC visit just before delivery, subjects were asked to recall all foods and beverages that they had consumed the previous two days from the time they woke up in the morning to the time of going to bed in the night and these were recorded on 24 hour recall forms for each participant. The subjects were required to recall all the foods consumed, the time the food was eaten, a description of the food item, method of preparation, ingredients used in food preparation and how much of the food was eaten. Bowls, cups, spoons and specifically designed food models and other standard cooking measures were carried by the Research Assistants to the health facilities on each day of data collection. These were presented to participants during the interviews to assist them in providing information on the quantities of each food that was consumed. Thorough and in-depth probing of participants and the use of these equipment enabled Research Assistants to verify the quantities of food that were consumed. After all foods and beverages were recorded follow up questions on snacks and any other foods were asked to make sure nothing was left out. A food frequency that was included in the 24 hour recall forms was also used to get other foods that the women may have consumed but could not remembered. Details of food consumption were recorded on 24 hour recall forms. It was administered during the first contact and at the end of the intervention in the hospitals' antenatal care sections.

The intervention involved the implementation of nutrition counselling to the cohorts. The study group underwent the current standard optimal care by the Ministry of Health and Nutrition Counselling which utilized counselling materials issued to the women after baseline information was collected. Overall, the intervention was a combination of counselling on dietary practices. The counselling resources that were used were a recipe booklet titled "Recipes for Good Nutrition; Nutrient Dense Local Dishes for Health. Easy to Prepare Mouth Watering Dishes" that contained easy to make dishes using locally available foods, a brochure with a title of "Sound Nutrition Benefits You and Your Baby" that contained information about best nutrition practices, and general care in pregnancy, a handout titled "Nutrition During Pregnancy and Breastfeeding that contained guidelines on proper feeding during pregnancy and a counselling chart that contained information on the suitable foods and best practices during all the months of pregnancy. The recipe booklet, the brochure and the chart were prepared by the researcher while the handout was adapted from materials developed by WHO for use in Tanzania and produced by GOK, UNICEF, WHO and USAID in 2007. The Counselling involved once monthly interaction with health worker for group counselling sessions using flip chart, and individual interaction with a recipe' booklet, a counselling brochure and a handout.

The women were instructed to read daily and apply the information obtained in the booklet and brochures. The brochures and booklet were translated to the local dialect 
for those who could not read and understand English. Those who were completely unable to read were instructed to use a family member who was to read and pass the information to them. During the bimonthly antenatal care visits the women were reminded to read the brochure, recipe booklet and hand out and apply the knowledge provided in those materials as well as information given during the counselling sessions. Through contact with the counselling materials, women were expected to have learnt and practised optimal feeding habits, and behaviours that would improve dietary intake. Duration of intervention was determined by the gestation age at recruitment and this ranged from four to seven months depending on the gestation age of every subject at recruitment. Pregnant women who underwent the exposure with counselling resources for a minimum of four months qualified for analysis.

Data collected were cleaned and entered into excel sheets at the end of every stage of data collection. Weights of foods consumed by the subjects from 24 hour recall were converted from household measures into grams and then into intake values for energy, protein, fat, iron, zinc, and vitamin A by Nutri-survey Computer Package. Local measuring utensils were identified and their weights and volumes determined. A calibrated list was then used on a variety of foods and beverages for the analysis. The data was then transferred to the Statistical Package for Social Sciences (SPSS) which was used for analysis. Descriptive statistics and t-tests were used to describe data.

\section{Logistical and ethical considerations}

A research permit was obtained from National Commission for Science, Technology and Innovation (NACOSTI). Permission to carry out research was sought from the Migori County Commissioner, County Director of Health and County Director of Education. Project administration was sought from the Medical Officers in Charge at all the selected health facilities. Participation in the study was purely voluntary and informed consent was obtained from the pregnant women who were then recruited into the $\mathrm{NCl}$ study. Data confidentiality was maintained. Standards and Operational Guidance for Ethics Review of Health Related Research with Human Participants by WHO (2011) was followed.

\section{RESULTS AND DISCUSSION}

\section{Nutrient intakes of pregnant women}

Twenty-four (24) hours recall interview was administered to the women to obtain nutrient intakes at baseline and was repeated at the end of the intervention. These interviews were done for two days for each respondent and the mean was computed as the daily nutrient intake. The nutrients that were considered during analysis were energy, proteins, carbohydrates, fats, dietary fibre, vitamin $\mathrm{A}$, vitamin $\mathrm{C}$, calcium, iron and zinc which are considered essential for pregnant women. The mean macronutrient intakes at baseline were $1613.03 \pm 439 \mathrm{Kcal}$ for energy, protein $62.61 \pm 23.56 \mathrm{~g}$ carbohydrates $244.93 \pm 65.16 \mathrm{~g}$, fat $40.54 \pm 23.22 \mathrm{~g}$ and after the intervention, mean energy intake was $2158.72 \pm 309.84$ Kcal, protein $85.52 \pm 23.83 \mathrm{~g}$, carbohydrates $311.66 \pm 58.41$ $\mathrm{g}$ and fat $60.79 \pm 24.64 \mathrm{~g}$. There was a marked improvement in the intakes for all the macronutrients after the intervention. Kilocalories increased by about 545 $\mathrm{Kcal}$, protein by about $22 \mathrm{~g}$, carbohydrates and fats, by about $66 \mathrm{~g}$ and $20 \mathrm{~g}$ respectively (Table 1 ).

The mean micronutrient intakes by the women at baseline for vitamin A was $1254.75 \pm 2131.48 \mu \mathrm{g}$, Folic acid, $196.95 \pm 67.22 \mu \mathrm{g}$, vitamin C $66.74 \pm 42.14 \mathrm{mg}$, calcium $299.71 \pm 142.51 \mathrm{mg}$, Iron $10.55 \pm 2.84 \mathrm{mg}$ and zinc $11.5 \pm 3.83 \mathrm{mg}$. The mean intakes after the intervention were vitamin A $1749.60 \pm 3560.43 \mu \mathrm{g}$, folic acid $249.37 \pm 67.20 \mu \mathrm{g}$, vitamin C $89.92 \pm 61.11 \mathrm{mg}$, calcium $441.96 \pm 177.93 \mathrm{mg}$, iron $14.87 \pm 3.17 \mathrm{mg}$ and zinc $15.62 \pm 3.74 \mathrm{mg}$. There was an increase in intakes of all micronutrients after the intervention. Vitamin A intake increased by about $45 \mu \mathrm{g}$, folic acid intake went up by about $52.42 \mu \mathrm{g}$, vitamin $\mathrm{C}$ went up by about $23.18 \mathrm{mg}$, calcium increased by about $142.25 \mathrm{mg}$, iron intake increased by about $4.32 \mathrm{mg}$ and zinc intake increased by about $4.12 \mathrm{mg}$ (Table 1).

Table 2 gives the proportions of the women who had nutrient intakes above or below RDA. For energy, $4.4 \%$ and $20.9 \%$ of the women had intakes above RDA at baseline and after the intervention respectively. For protein, $62.5 \%$ and $84.3 \%$ of the women had intakes above RDA at baseline and after intervention respectively. Carbohydrate intake had $93.9 \%$ of the women within or above RDA at baseline while all the women were able to meet the RDA requirement at the end of the intervention. For vitamin $A, 61.2 \%$ and $77.4 \%$ of the women were able to meet the RDA requirements at baseline and after the intervention respectively. For folic acid only $13.5 \%$ and iron $13.5 \%$ of the women managed to meet the RDA requirement at baseline but surprisingly after the intervention all the women had intakes below the RDA. The proportions meeting the RDA requirement for calcium were quite low at baseline $(1.4 \%)$ and even after the intervention $(1.7 \%))$. The proportion of women who had met the RDA requirement for zinc intake was less than half $(23.8 \%)$ but increased to more than half $(52.2 \%)$ after the intervention. In Table 3, only vitamin A (2.714, $P \leq 0.05)$, carbohydrate $(20.454, P \leq 0.05)$, fiber (3.831, $P \leq 0.05)$ and vitamin $C(3.378, P \leq 0.05)$ had significant differences between their means and the reference values at baseline. After intervention protein (11.935, 
Res. J. Food Sci. Nutr.

Table 1.Nutrient Intakes of Pregnant Women.

\begin{tabular}{lcccccc}
\hline \multirow{2}{*}{ Nutrient } & \multicolumn{3}{c}{ Baseline $(\mathbf{N}=\mathbf{1 3 6})$} & \multicolumn{2}{c}{ Post-Intervention (N= 115) } \\
\cline { 2 - 7 } & Mean & Std. Dev & \% RDA & Mean & Std. Dev & $\%$ RDA \\
\hline Energy $($ Kcal) & 1613.03 & 439.005 & 66.90 & 2158.72 & 309.837 & 89.94 \\
Water $(\mathrm{g})$ & 941.97 & 358.227 & 94.1 & 1170.93 & 318.987 & 117.09 \\
Protein $(\mathrm{g})$ & 62.61 & 23.358 & 88.18 & 85.52 & 23.830 & 120.45 \\
Carbohydrates $(\mathrm{g})$ & 244.93 & 65.162 & 139.96 & 311.66 & 58.405 & 178.0 \\
Dietary fiber $(\mathrm{g})$ & 31.18 & 10.055 & 111.36 & 39.87 & 8.017 & 142.39 \\
Vitamin A $(\mu \mathrm{g})$ & 1254.75 & 2031.485 & 162.95 & 1749.60 & 3560.428 & 227.22 \\
Folic Acid $(\mu \mathrm{g})$ & 196.95 & 67.220 & 32.82 & 249.37 & 67.196 & 41.56 \\
Vitamin C $(\mathrm{mg})$ & 66.74 & 42.143 & 78.51 & 89.92 & 61.107 & 105.78 \\
Calcium $(\mathrm{mg})$ & 299.71 & 142.511 & 29.97 & 441.96 & 177.930 & 44.19 \\
Iron $(\mathrm{mg})$ & 10.55 & 2.846 & 39.07 & 14.87 & 3.172 & 55.07 \\
Zinc $(\mathrm{mg})$ & 11.51 & 3.829 & 104.63 & 14.62 & 3.741 & 132.90 \\
\hline
\end{tabular}

RDA obtained from: Food and Nutrition Board, Institute of Medicine, National Academies, 2011. Dietary Reference Intakes (DRIs), Recommended Dietary allowances and Adequate Intakes, DRI table and Application Reports. USDA, United States Department of Agriculture (2011), National Agricultural Library, Food and Nutrition Centre. www.nal.usda.gov./fnic/dri-tables.

Table 2.Proportion of pregnant women with nutrient intakes above/below RDA.

\begin{tabular}{|c|c|c|c|c|c|c|c|c|}
\hline \multirow{3}{*}{ Nutrient } & \multicolumn{4}{|c|}{$\geq$ RDA } & \multicolumn{4}{|c|}{$<$ RDA } \\
\hline & \multicolumn{2}{|c|}{ Baseline } & \multicolumn{2}{|c|}{ Post intervention } & \multicolumn{2}{|c|}{ Baseline } & \multicolumn{2}{|c|}{ Post intervention } \\
\hline & Number & Percent & Number & Percent & Number & Percent & Number & Percent \\
\hline Energy & 6 & 4.4 & 24 & 20.9 & 130 & 95.6 & 91 & 79.1 \\
\hline Protein & 85 & 62.5 & 97 & 84.3 & 51 & 37.5 & 18 & 15.7 \\
\hline $\mathrm{CHO}^{*}$ & 128 & 93.9 & 115 & 100 & 8 & 6.1 & 0 & 0 \\
\hline Vitamin C & 33 & 24.5 & 53 & 46.1 & 103 & 75.5 & 62 & 53.9 \\
\hline Vitamin A & 83 & 61.2 & 89 & 77.4 & 53 & 38.8 & 26 & 22.6 \\
\hline Folic Acid & 18 & 13.5 & 0 & 0 & 118 & 86.5 & 115 & 100 \\
\hline Calcium & 2 & 1.4 & 2 & 1.7 & 134 & 98.6 & 113 & 98.3 \\
\hline Iron & 18 & 13.5 & 0 & 0 & 118 & 86.5 & 115 & 100 \\
\hline Zinc & 32 & 23.8 & 60 & 52.2 & 104 & 76.2 & 55 & 47.8 \\
\hline
\end{tabular}

${ }^{*} \mathrm{CHO}$ - Carbohydrate. RDA obtained from: Food and Nutrition Board, Institute of Medicine, National Academies, 2011.

$\mathrm{P} \leq 0.05)$, carbohydrate $(32.437, \mathrm{P} \leq 0.05)$ vitamin $\mathrm{A}$ (2.860, $P \leq 0.05)$, fiber $(15.877, P \leq 0.05)$ and vitamin $C(6.128$, $P \leq 0.05)$ had significant differences between their means and the reference values.

Of the nutrients that were analyzed, only zinc, vitamin A, carbohydrate and fiber intakes were above RDA at baseline. After the intervention, percentage of RDA went up for all nutrients except that energy, folic acid, calcium and iron intakes had increased but were still below the RDA. Intakes of zinc, vitamin A and carbohydrate were above RDA at both baseline and after the intervention. Percentages of RDA for folic acid, iron and calcium at baseline were less than average and only percentage of RDA for iron managed to rise to slightly above average after intervention (Table 2). A few of the women managed to meet the RDA requirement for folic acid and iron at baseline but surprisingly after the intervention all the women had intakes below the RDA. This finding on iron and folic acid intakes confirms that diets of women in poor settings are usually deficient in iron and folic acid. Linkage Project (2001) stated that the diet of populations in developing countries cannot meet all of the iron requirements of pregnant women especially those who begin pregnancy on low reserves. This may explain why iron intake was below the RDA even after the intervention for many women, however most of the women were not iron deficient, their serum iron levels may have been boosted by the iron and folic acid supplements given at the antenatal care during each visit.

Intake of nutrients below RDA can be a risk factor for nutritional deficiencies. According to Linkage Project (2001) deficiencies in iron, vitamin A, calcium and folic 
Table 3. Test (t-test) for relationship between Nutrient intake and reference intakes.

\begin{tabular}{|c|c|c|c|c|c|c|}
\hline \multirow[b]{2}{*}{ Nutrients } & \multicolumn{3}{|c|}{ Post Intervention } & \multicolumn{3}{|c|}{ Baseline } \\
\hline & $\mathbf{t}$ & Significant & $\begin{array}{c}\text { Mean } \\
\text { Difference }\end{array}$ & $\mathbf{t}$ & Significant & $\begin{array}{c}\text { Mean } \\
\text { Difference }\end{array}$ \\
\hline Energy (Kcal) & -20.630 & 0.000 & -746.973 & -6.966 & 0.000 & -201.278 \\
\hline Protein (g) & 1.871 & 0.063 & 3.605 & 11.935 & 0.000 & 26.522 \\
\hline Carbohydrate (g) & 20.454 & 0.000 & 109.932 & 32.437 & 0.000 & 176.661 \\
\hline Vitamin A & 2.714 & 0.007 & 454.748 & 2.860 & 0.005 & 949.600 \\
\hline Folic Acid & -72.698 & 0.000 & -403.054 & -55.958 & 0.000 & -350.635 \\
\hline Vitamin C & 3.378 & 0.001 & 11.741 & 6.128 & 0.000 & 34.922 \\
\hline Calcium & -59.579 & 0.000 & -700.293 & -33.633 & 0.000 & -558.043 \\
\hline Iron & -95.644 & 0.000 & -22.449 & -61.294 & 0.000 & -18.130 \\
\hline Zinc & -11.050 & 0.000 & -3.490 & -1.097 & 0.275 & -.383 \\
\hline Fiber & 3.831 & 0.000 & 3.177 & 15.877 & 0.000 & 11.870 \\
\hline
\end{tabular}

$\mathrm{df}=136$ (Baseline), 115 (Post intervention), P $\leq 0.05$. RDA obtained from: Food and Nutrition Board, Institute of Medicine, National Academies, 2011. $t=t$ value for paired T-test.

acid among others can lead to increased risk of low birth weight and preterm births as well as foetal deaths. At baseline vitamin $A$, carbohydrate, fiber and vitamin $C$ had positive and significant differences between their means and the reference values at baseline $(P \leq 0.05)$ implying that more nutrient intakes were lower than the reference values. At post intervention all the nutrients except zinc had no statistically significant differences between their means and reference intake values. These findings suggest that there were higher intakes of carbohydrate, vitamin $A$ and vitamin $C$ and lower intakes of energy, folic acid, calcium, zinc and iron at baseline compared with reference intakes.

Intakes of Protein, carbohydrates, vitamin C, and vitamin A were higher and intakes of energy, folic acid, calcium and iron were lower than the reference intakes at post intervention. Therefore, more nutrients had intakes higher than RDA after the intervention. The findings from this study on nutrient intake at baseline are consistent with those obtained by Odiwuor et al. (2013) in the same area of study that found intake of all nutrients except vitamin $\mathrm{C}$ and fiber to be below RDA. However intakes after the intervention were above RDA for most nutrients indicating that the situation of nutrient intake in this study area had not changed but that the nutrition counselling may have influenced positively intake of nutrients among the pregnant women in this study.

These findings support the Kenya Situation Analysis Report that micronutrient deficiencies are common among pregnant women and under-fives and specifically that of vitamin $A$, zinc, iron and iodine deficiencies are the most prevalent (MoPHS and SCUK, 2011). A Malawian study (Hjerthol et al, 2017) found that the percentage of women who had consumed animal protein foods rich in essential micronutrients was quite low. It was observed in their finding that more than half of all participants were at risk of inadequate intake of most micronutrients. This is in agreement with the findings from this study that showed inadequate intake of several essential micronutrients.

A Sri Lankan study (Adikari et al, 2016) found a mean energy intake of 2472 Kcals, protein intake of $74 \mathrm{~g}$ and vitamin $C$ intake of $71 \mathrm{mg}$. These intakes were above the RDA while iron intake $(17 \mathrm{mg})$, calcium intake $(845 \mathrm{mg})$, folic acid intake $(421 \mu \mathrm{g})$ and vitamin A intake $(526 \mu \mathrm{g})$ were all below the RDA. Similarly, it was found that iron, calcium and folic acid were below RDA both at baseline as well as after intervention. Vitamin A was above RDA for this study at both baseline and after intervention; however, energy, protein and vitamin $C$ intake were below RDA at baseline but protein and vitamin $\mathrm{C}$ intake increased above RDA after the intervention. These findings show that even with nutrition interventions in place it may still be difficult to attain the recommended intakes of iron, folic acid and calcium for pregnant women in rural areas of developing country set ups.

The effect of nutrient deficiencies on foetal growth will differ depending on the time they occur (Bloem, 2013). Third trimester is the time of most rapid weight gain of the foetus, other foetal outcomes like foetal length gain peaks before this period. A study on maternal dietary intake during pregnancy and its associations to birth size in rural Malawi (Hjertholm et al, 2017) found that more than $50 \%$ of the women had intakes below RDA for most nutrients. This compared with the findings of this study where there was inadequacy for some nutrients such as energy, folic acid, iron and calcium.

Energy, protein, fat, carbohydrate, fiber, vitamin C, calcium, iron and zinc intakes at baseline and at the end of the intervention had a statistically significant difference in their means at $p \leq 0.05$. Only vitamin A intake had no significant difference between its mean at baseline and 
Res. J. Food Sci. Nutr.

Table 4. Test for associations between means of nutrient intakes at baseline and after the intervention.

\begin{tabular}{lcccccc}
\hline Nutrient & Correlation & Significant & Mean & Std. Dev & t & Significant \\
\hline Energy $($ Kcal) & 0.002 & 0.987 & 541.194 & 544.496 & 10.087 & 0.000 \\
Protein $(\mathrm{g})$ & -0.030 & 0.764 & -21.252 & 33.882 & 6.366 & 0.000 \\
Fat $(\mathrm{g})$ & 0.047 & 0.639 & -18.913 & 31.772 & 6.041 & 0.000 \\
Carbohydrates $(\mathrm{g})$ & 0.026 & 0.792 & -70.262 & 89.020 & 8.010 & 0.000 \\
Dietary fiber $(\mathrm{g})$ & 0.096 & 0.337 & -9.136 & 12.331 & 7.519 & 0.000 \\
Vitamin A $(\mu \mathrm{g})$ & 0.040 & 0.689 & -462.699 & 4328.985 & 1.085 & 0.281 \\
Folic acid $(\mu \mathrm{g})$ & 0.032 & 0.750 & -48.311 & 95.337 & 5.143 & 0.000 \\
Vitamin C $(\mathrm{mg})$ & 0.063 & 0.525 & -22.136 & 74.624 & 3.011 & 0.003 \\
Calcium $(\mathrm{mg})$ & 0.108 & 0.275 & -140.291 & 220.048 & 6.470 & 0.000 \\
Iron $(\mathrm{mg})$ & -0.063 & 0.526 & -4.175 & 4.508 & 9.399 & 0.000 \\
Zinc $(\mathrm{mg})$ & -0.004 & 0.971 & -2.990 & 5.311 & 5.714 & 0.000 \\
\hline
\end{tabular}

$\mathrm{P} \leq 0.05$, RDA obtained from: Food and Nutrition Board, Institute of Medicine, National Academies, 2011. $\mathrm{t}=\mathrm{t}$ value for paired T-test.

Table 5. Mean number of times foods in various food groups were consumed.

\begin{tabular}{lcc}
\hline Food Group & $\begin{array}{c}\text { Frequency/Week } \\
\text { (Baseline) }\end{array}$ & $\begin{array}{c}\text { Frequency/Week (Post } \\
\text { Intervention) }\end{array}$ \\
\hline Cereal grains, starches & 396 & 340 \\
Meats \&Poultry & 56 & 68 \\
Fishes & 51 & 92 \\
Vegetables & 569 & 505 \\
Fruits & 65 & 92 \\
Eggs \& Dairy products & 57 & 95 \\
Beverages & 137 & 98 \\
Fats \& Oils & 174 & 162 \\
\hline
\end{tabular}

after intervention indicating that there were major positive changes in intakes of these nutrients except vitamin A (Table 4). There is a difference between the two findings however since for the Malawian study (Hjertholm et al., 2017) all the nutrients did not meet RDA while in this study only five out of eleven nutrients failed to meet the RDA after intervention. Mean energy intake (2096 kcal) was slightly lower than energy intake for this study (2158 Kcal). These study findings underscore the important benefit which nutrition policies directed towards food based approaches can produce even in situations where resources are scarce. Although food security may not be ensured, it can still be practical to promote an optimal diet based on local foods to ensure adequate foetal growth.

\section{Distribution of foods consumed by pregnant women according to food groups}

Dietary intake from 24 hours recall of two days was used to obtain mean food distribution according to food groups (Table 5). At baseline vegetables was the most consumed (569) followed by cereals, grains and starches
(396), fats and oils (174) and beverages (137). After the intervention the same food groups were mostly consumed but the frequencies of consumption reduced. Consumption of fish, meat, eggs, dairy products and fruits went up after the intervention but consumption of beverages and oils and fats reduced. Odiwuor et al. (2013) in a study on dietary intake in the same study area found that pregnant women consumed mostly carbohydrates followed by proteins then vegetables. A Migori County Fact Sheet also reports (KIRA, 2015) that grains was the most consumed followed by green vegetables.

This study finding presents a slight variation from the two previous findings (Odiwuor et al., 2013; KIRA, 2015). The pattern seems to have changed slightly as the women consumed mostly vegetables followed by carbohydrates at baseline. The reduction in consumption of vegetables and carbohydrates after the intervention may be attributed to increased intake of food from other food groups such as meats, fishes, eggs and dairy products. Increased intake of fruits, meats, fishes, eggs and dairy may indicate that the women's diet had become more diversified and included all food groups at proper 
quantities unlike before when intake of only two food groups that is carbohydrates and vegetables was dominant. Intake of fats and oils and beverages reduced after intervention. According to a FAO fact sheet (2012) the recommendation for pregnant women is five food groups that is, grains, fruits, vegetables proteins and dairy products with less intake of fats and beverages.

The beverages consisted mainly of tea and caffeinated soft drinks which would contribute to unavailability of nutrients. Reduction in consumption of beverages was therefore a sound practice according to FAO (2012) and Pestoa et al. (2016). The women seem to have gained some nutrition knowledge and skills that enabled them to acquire sound feeding practices. An Indian study which obtained positive pregnancy outcomes observed that pregnant women had reasonable intakes of milk, poultry, meat, fish, eggs and beans (Madan, et al, 2017). This confirms the necessity of adequate consumption of all nutrients and especially protein rich foods during pregnancy.

\section{Conclusion}

Intakes of protein, carbohydrate, vitamin $\mathrm{C}$ and vitamin $\mathrm{A}$ were adequate while intake of energy, folic acid, calcium and iron were still inadequate after the intervention. Folic acid, calcium and iron were inadequate at baseline and even after the intervention. Vegetables and cereals were the most consumed food groups. Consumption of fish, meat, eggs and dairy products increased while oils and fats and beverages reduced after the intervention. More diet diversification was achieved during the intervention.

The study recommends to the National and county government and other agencies concerned with maternal health that nutrition policies should be directed towards a food based approach where pregnant women are targeted to promote optimal diversified diets based on local foods. Agri-food policies should also be directed at promoting increased food productivity and diversified food consumption at the household level.

Interventions aimed directly at meeting adequate intakes of these nutrients such as supplementation should be introduced and enhanced. Those that are already in place such as iron and folic acid supplementation by the government need to be evaluated and the pregnant women tracked to ensure total compliance. Other long term strategies such as biofortification and post-harvest fortification for calcium, folic acid and other essential micronutrients need to be considered.

\section{CONFLICT OF INTEREST}

The authors declare that they have no conflict of interest.

\section{ACKNOWLEDGEMENT}

We acknowledge the staff at the sub-County hospitals of study, the nurses who participated in the counselling initiative, the Research Assistants and the mother mentors for their resilience and determination during data collection and the study participants; their time and energy to provide information and their acceptance to spend time to read and utilize the counselling materials and bear the burden of being followed up through pregnancy and delivery is an immense contribution to the success of this work. The partial financial support of Rongo University is also appreciated.

\section{REFERENCES}

Adikari, A. M. N. T., Sivakanesan, R., Wijesinghe D., \&Liyange, C. (2016). Assessment of Nutritional Status of Pregnant Women in a Rural Area in Sri Lanka.Tropical Agriculture Research, 27(2), 203-211.

Black, R. E., Victoria C. G., \& Walker, S. P. (2013). Maternal and Child Undernutrition and overweight in low income and middle income Countries. Lancet 3, 382, 427-451.

Bloem, M. (2013). Preventing Stunting; Why it matters; What it takes: The Road to Good Nutrition; A Global Perspective. Krager S. Library of Congress, Germany.

ECOSOC (2007). Strengthening Efforts to Eradicate Hunger.Report.

FAO (2012). FAO Fact Sheet. Web MD Medical Reference. Web MD LCC. p. 1

FAO (2014). Better Nutrition Better Lives. Hunger Facts: Second International Conference on Nutrition. Rome, Italy

FAO (2017). FAO's Role in Nutrition.FAO of the United Nations. Available at www.fao.org/nutrition

Fisher, A. A, Laing, J. E, Stoeckel, J. E, \& Townsend, J. W. (1991). Handbook for Family Planning Operations Research Design. 2nd Ed. Population Council, New York, USA. p. 43.

Hjerthol, K. G., Iverson, P. O., Otteson, G. H., Mdala, H., Munthali, A., Maleta, K., Shi, Z., Ferguson, E., \& Kamudoni, P. (2017). Maternal Dietary intake during Pregnancy and its association to Birth Size in Rural Malawi: A Cross-sectional Study. Maternal and child nutrition. Wiley online Library. John Wiley and Sons.

Leslie, J. (2000). Women's Nutrition the key to Improving Family health in Developing Countries. Health Policy Plan 1991, 6, 1-19.

Linkage Project (2001). Essential Health Sector Actions to Improve Maternal Nutrition in Africa.Academy for Educational Development. Washington.

Kenya Interagency Rapid Assessment (KIRA) (2015). Migori Secondary Data Review.

Madan, E., Has, J. D., Manon, P., Kumar.V., Kuma, A., and \& Singh, S., \& Dixit, S. (2017). Seasonal Differences in Birth Weight and Lengths depends on Exposure during Pregnancy in Rural India. The Faseb Journal, 31(1), 639-649.

Merkel, K. (2016). Women and Hunger Facts: World Hunger Education Services.

Available at https://www.worldhunger.org/women-and-hunger-facts/ .

Ministry of Public Health Services (Kenya) \& Save the Children 
Res. J. Food Sci. Nutr.

UK (MoPHS \& SCUK) (2011). Nutrition Situation in Kenya.Report.

NCP (Nutrition Communication Project) (1995). Niger vitamin A promotion project 1991-1995. Final Report. Washington Academy for Educational Development.

Nutrition Division GOK (2012). National Nutrition Action Plan $2012-2017$.

Odiwuor, F. A., Kimiywe, J., Kenneth, O. O., \&Rombo, G. (2013). Energy Intake, Physical Activity and Gestational Weight gain among Pregnant Women at Rongo sub-District Hospital. African Journal of Education, Science and Technology, 1(3), 73-80.

Pestoa, M. C., Meudes, L. L., Gomez, C. S., Martins, P. A., \& Menendez, V. (2016). Food Environment and Fruit and Vegetable Intake in an Urban Population.A Multilevel Analysis. BMC Public Health 15(1), 10-12.

Ransom, E. I., \& Elder, L. K. (2003). Nutrition of Women and Adolescent Girls: Why It Matters. http://www.prb.org/Publications/Articles/2003/NutritionofWom enandAdolescentGirlsWhyltMatters.aspx.

Republic of Kenya (2011). Maternal, Infant and Young Child Nutrition: National Operational Guidelines for Health Workers. Ministry of Health.

Republic of Kenya (2008). Food Security and Nutrition Strategy (FSNS). Available at http://www.fao.org/rightto food/inaction/countrylist/kenya/kenyaFSNsfinal draft.pdf.
Roesel, C., Schafter, T., Durongdej, S., \& Tokmoh, L. (1990). Effects of improved weight monitoring feedback during pregnancy in a Khmar refugee camp in Thailand. Maternal nutrition and health care program. Research Report Series. Report No. 16. Washington.

Ruel, M. (2013). Food Security and Nutrition Linkage and Complimentaries: The Road to Good Nutrition;A Global Perspective. Krager S. Library of Congress, Germany.

Schultink, W. (2011). How to improve Nutrition via Effective Programming: The Road to Good Nutrition; A Global Perspective. Krager S. Library of Congress, Germany.

Shrimpton, R., \& Sadanha, L. (2011). The Kenya Nutrition Programme Review KNPR. Public Nutrition Solutions Ltd (PNSS).

United States Department of Agriculture (USDA) (2011). DRI Tables and Application Reports. Nutrition and Agriculture Library, Food and Nutrition Information Centre.

WHO (2011). Standards and Operational Guidance for Ethics Review of Health-Related Research with Human Participants. Geneva, Switzerland.

Yamane, T. (1967). Elementary Sampling Theory. Eaglewood Cliffs, N. J: Prentice - Hall. 